\title{
Endocardial fibroelastosis in infants with hydrops fetalis
}

\author{
M J Newbould, G R Armstrong, A J Barson
}

\begin{abstract}
Endocardial fibroelastosis, defined as an endocardium in excess of $30 \mu \mathrm{m}$ thick, was found in 10 out of 34 cases of hydrops fetalis in a review of 1589 perinatal necropsies carried out between 1976 and 1989. The infants comprised 16 cases of rhesus haemolytic disease, of whom three had endocardial fibroelastosis, and 18 cases of non-rhesus hydrops, of whom seven had endocardial fibroelastosis. Intrauterine congestive heart failure was thought to have been the probable cause of hydrops in eight of the 10 infants with endocardial fibroelastosis. None of an age matched control group without endocardial fibroelastosis had evidence of congestive cardiac failure. These observations support the hypothesis that endocardial fibroelastosis is an endocardial response to chronic prenatal myocardial stress.
\end{abstract}

Endocardial fibroelastosis in the newborn is characterised by a generalised thickening of the ventricular endocardium which renders it an opaque creamy-white when examined by the naked eye (fig 1). The affected ventricular cavity is commonly dilated and globular in shape and the left ventricle is more frequently affected than the right. Microscopically the endocardium stains intensely for elastin (figs 2

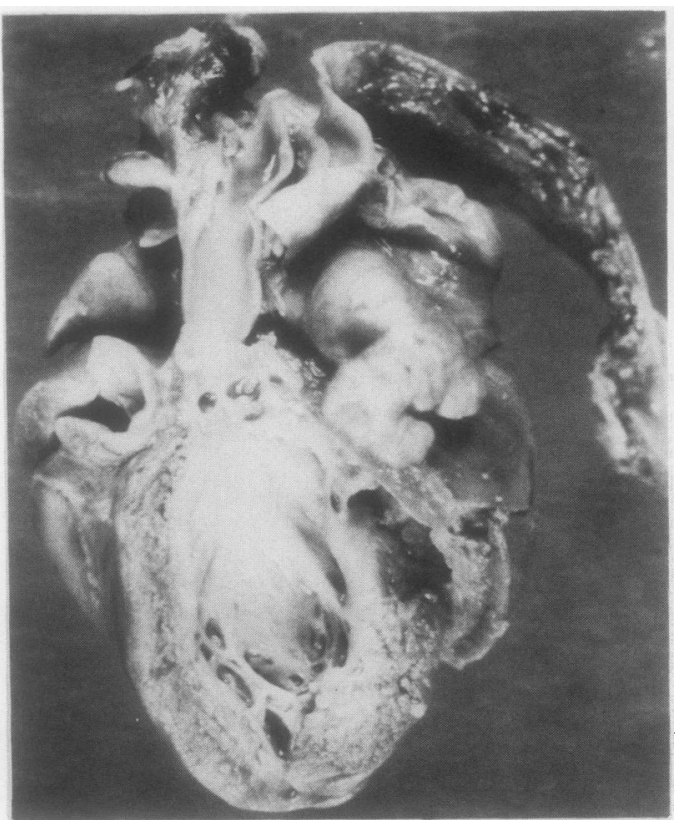

Figure 1 A heart from an infant with endocardial fibroelastosis, showing the pale, opaque endocardium. and 3). Endocardial fibroelastosis is conventionally classified into primary and secondary forms according to whether a structural cardiac malformation is also present. ${ }^{1}$

An alternative view is to regard endocardial fibroelastosis as a non-specific response to chronic myocardial dysfunction, so that all cases are secondary not only to cardiac malformation but also to non-structural causes such as cardiomyopathies which induce myocardial stress. ${ }^{2-4}$ As a clinical problem endocardial fibroelastosis commonly presents itself in infancy or adolescence. ${ }^{5}$ If endocardial fibroelastosis is a non-specific response to myocardial dysfunction, however, it may also be expected to occur in late fetal life in association with intrauterine hydrops which is a common manifestation of prenatal congestive heart failure. This is a well documented association $^{6}$ and the purpose of this study is to examine it in the light of this hypothesis.

\section{Methods}

All the perinatal necropsies performed in St Mary's Hospital, Manchester, between 1976 and 1989 were reviewed. From the total of 1589 cases, the paraffin wax embedded blocks

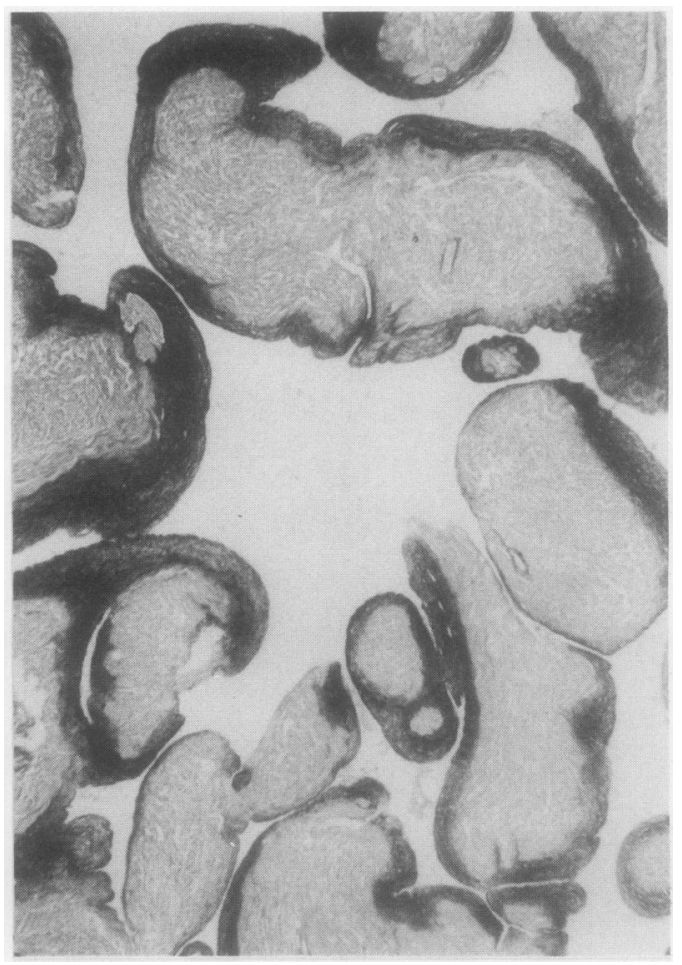

Figure 2 Case 2: low power view of endocardial fibroelastosis (elastic van Gieson stain). 
Figure 3 Case 3: high power view of endocardial fibroelastosis (elastic van Gieson stain).

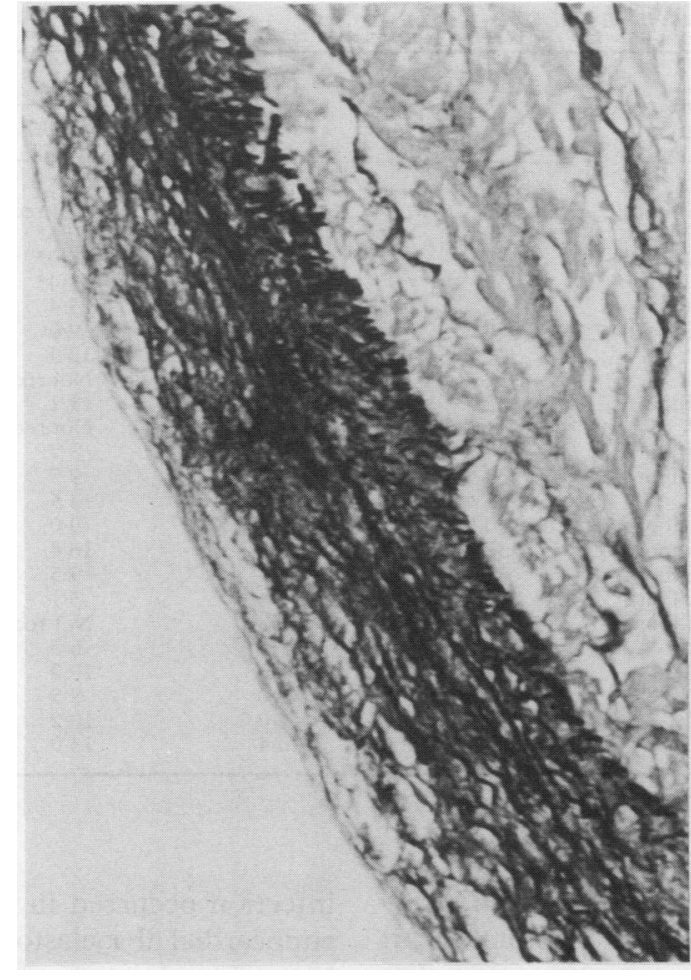

of cardiac tissue from 34 infants with hydrops fetalis were re-examined. Of these, 16 infants had rhesus haemolytic disease and 18 were cases of non-rhesus hydrops. Sections $5 \mu \mathrm{m}$ thick were recut from blocks taken transversely to show both ventricles and were stained by the elastic van Gieson method. Two infants with rhesus haemolytic disease but without hydrops were also included in the study. Cases of endocardial fibroelastosis in malformed hearts not associated with hydrops were excluded. Comparison was made with similar blocks from 10 control necropsies matched for gestation and duration of postnatal survival in whom hydrops fetalis or rhesus incompatibility were absent. Though there has been an attempt to take standard blocks from autopsy material over the years, precise equivalence is difficult to attain, particularly in the abnormal hearts which form the subject matter of the study. This archival material was not therefore suitable for detailed morphometry but numerical data were obtained using the Seescan Image Analysis System. The mean endocardial thickness was calculated to the nearest $5 \mu \mathrm{m}$ from 10 random measurements made per microscopic field in 10 to 80 fields examined per section.

Cardiac weights were compared with a normal range for gestation. ${ }^{7}$

\section{Results}

All of the 10 control cases had a mean endocardial thickness of less than $5 \mu \mathrm{m}$ and similar results were obtained on assessing the two infants with rhesus incompatibility not accompanied by hydrops.

Initially, the 34 cases (tables 1 and 2) were assessed independently by two pathologists who were unanimous in their decision that cases 1 to 10 (table 1 ) showed an abnormal degree of endocardial fibroelastic thickening by standard light microscopy. Subsequently mean endocardial thickness was calculated and in these infants was at least $30 \mu \mathrm{m}$. Therefore, as this seemed to be the thickness at which the endocardium could be perceived as abnormal, endocardial fibroelastosis was defined as an endocardial thickness of $30 \mu \mathrm{m}$ or greater. Thus 10 of the $34(29 \%)$ infants with hydrops fetalis were considered to have endocardial fibroelastosis. Three of this group had rhesus incompatibility and seven were cases of non-rhesus hydrops. Table 2 shows, however, that there is a gradation in mean endocardial thickness-for example, a further six infants had measurements between 15 and $25 \mu \mathrm{m}$ (cases 11 to 16 ) (table 2). There were strong grounds for believing that chronic intrauterine cardiac failure was an aetiological factor leading to hydrops in 13 of the 16 infants with an endocardial thickness of $15 \mu \mathrm{m}$ or more. Hydropic infants within this range of mean endocardial thickness were more likely to have cardiac hypertrophy. Nine of them had cardiac weights in excess of the mean plus 2 standard deviations for their gestation. None of the 15 hydropic infants with mean endocardial thickness of less than $15 \mu \mathrm{m}$ where the heart weight was known had this degree of cardiomegaly (table 2).

In all of four infants with endocardial fibroelastosis where both ventricles could be examined histologically the endocardial thickening involved both right and left sides. Only a single ventricle was available for retrospective histological examination in the other six cases of endocardial fibroelastosis, which included the three examples with malformed hearts, and accurate orientation was not possi-

Table 1 Hydropic infants with endocardial fibroelastosis

\begin{tabular}{|c|c|c|c|c|c|c|c|}
\hline \multirow[b]{2}{*}{ Case No } & \multirow[b]{2}{*}{ Sex } & \multirow[b]{2}{*}{ Associated pathology } & \multirow{2}{*}{$\begin{array}{l}\text { Survival } \\
\text { (days) }\end{array}$} & \multirow{2}{*}{$\begin{array}{l}\text { Gestation } \\
\text { (weeks) }\end{array}$} & \multicolumn{2}{|c|}{ Heart weight $(g)$} & \multirow{2}{*}{$\begin{array}{l}\text { Mean endocardial } \\
\text { thickness (to } \\
\text { nearest } 5 \mu \mathrm{m})\end{array}$} \\
\hline & & & & & Expected & Recorded & \\
\hline 1 & $\mathbf{M}$ & Cardiac malformation & $<1$ & 34 & $13 \cdot 4$ & $30 \cdot 0^{\star}$ & 100 \\
\hline 2 & $\mathbf{F}$ & Cardiac malformation & Stillborn & 30 & $9 \cdot 3$ & $22 \cdot 8^{\star}$ & 90 \\
\hline 3 & $\mathbf{F}$ & Rhesus incompatibility & Stillborn & 34 & $13 \cdot 4$ & $14 \cdot 6$ & 55 \\
\hline 4 & $\mathbf{F}$ & Intracranial haemangioma & Stillborn & 32 & $11 \cdot 0$ & $36 \cdot 2^{\star}$ & 45 \\
\hline 5 & $\mathrm{~F}$ & Cardiac malformation & Stillborn & 28 & 7.6 & 3.5 & 40 \\
\hline 6 & $\mathbf{F}$ & Rhesus incompatibility & $<1$ & 28 & $7 \cdot 6$ & $13 \cdot 0^{\star}$ & 35 \\
\hline 7 & $\mathbf{M}$ & Parvovirus infection & $<1$ & 28 & 7.6 & $10 \cdot 5^{\star}$ & 35 \\
\hline 8 & $\mathbf{F}$ & Idiopathic, pulmonary hypoplasia & $<1$ & 24 & 4.9 & 3.0 & 35 \\
\hline 9 & $\mathbf{M}$ & Rhesus incompatibility & Stillborn & 31 & $10 \cdot 0$ & $12 \cdot 8$ & 30 \\
\hline 10 & $\mathrm{~F}$ & Idiopathic (?haemolysis) & $<1$ & 36 & $15 \cdot 1$ & $12 \cdot 0$ & 30 \\
\hline
\end{tabular}

${ }^{\star}$ Denotes heart weight in excess of 2 standard deviations above the mean for gestation 
Table 2 Hydropic infants with endocardium of less than $30 \mu \mathrm{m}$ in thickness

\begin{tabular}{|c|c|c|c|c|c|c|c|}
\hline \multirow[b]{2}{*}{ Case No } & \multirow[b]{2}{*}{ Sex } & \multirow[b]{2}{*}{ Associated pathology } & \multirow{2}{*}{$\begin{array}{l}\text { Survival } \\
\text { (days) }\end{array}$} & \multirow{2}{*}{$\begin{array}{l}\text { Gestation } \\
\text { (weeks) }\end{array}$} & \multicolumn{2}{|c|}{ Heart weight $(g)$} & \multirow{2}{*}{$\begin{array}{l}\text { Mean endocardial } \\
\text { thickness (to } \\
\text { nearest } 5 \mu \mathrm{m} \text { ) }\end{array}$} \\
\hline & & & & & Expected & Recorded & \\
\hline 11 & $\mathrm{~F}$ & Rhesus incompatibility & $<1$ & 32 & $11 \cdot 0$ & $15 \cdot 5^{\star}$ & 25 \\
\hline 12 & $\mathrm{~F}$ & Rhesus incompatibility & Stillborn & 36 & $15 \cdot 1$ & Not recorded & 25 \\
\hline 13 & $\mathrm{M}$ & Rhesus incompatibility & 11 & 36 & $15 \cdot 1$ & $20 \cdot 0^{\star}$ & 25 \\
\hline 14 & $M$ & Rhesus incompatibility & 32 & 27 & $7 \cdot 6$ & $10 \cdot 0^{\star}$ & 15 \\
\hline 15 & $\mathbf{M}$ & Rhesus incompatibility & $<1$ & 33 & $12 \cdot 0$ & $17 \cdot 4^{\star}$ & 15 \\
\hline 16 & $\mathbf{M}$ & Idiopathic & 16 & 38 & $20 \cdot 4$ & $24 \cdot 4$ & 15 \\
\hline 17 & $M$ & Rhesus incompatibility & Stillborn & 29 & $9 \cdot 3$ & $9 \cdot 0$ & 10 \\
\hline 18 & $M$ & Rhesus incompatibility & 25 & 31 & $10 \cdot 0$ & $12 \cdot 4$ & 10 \\
\hline 19 & $\mathrm{~F}$ & Rhesus incompatibility & 8 & 32 & $11 \cdot 0$ & Not recorded & 10 \\
\hline 20 & M & Rhesus incompatibility & Stillborn & 32 & $11 \cdot 0$ & $11 \cdot 1$ & 10 \\
\hline 21 & M & Idiopathic, adrenal hypoplasia & 17 & 41 & 21.9 & Not recorded & 10 \\
\hline 22 & $\mathrm{~F}$ & Rhesus incompatibility & Stillborn & 27 & $7 \cdot 6$ & $8 \cdot 7$ & $<5$ \\
\hline 23 & $\mathrm{~F}$ & Rhesus incompatibility & Stillborn & 34 & $13 \cdot 4$ & $9 \cdot 5$ & $<5$ \\
\hline 24 & $\mathbf{F}$ & Rhesus incompatibility & 52 & 38 & $20 \cdot 4$ & $13 \cdot 5$ & $<5$ \\
\hline 25 & $\mathbf{F}$ & Rhesus incompatibility & Stillborn & 30 & $9 \cdot 3$ & $9 \cdot 0$ & $<5$ \\
\hline 26 & $\mathrm{~F}$ & Twin-twin transfusion & Stillborn & 37 & $16 \cdot 0$ & $16 \cdot 4$ & $<5$ \\
\hline 27 & $\mathrm{~F}$ & Cardiac malformation & Stillborn & 34 & $13 \cdot 4$ & $9 \cdot 5$ & $<5$ \\
\hline 28 & $\mathrm{~F}$ & Idiopathic, pulmonary hypoplasia & Stillborn & 28 & $7 \cdot 6$ & $3 \cdot 1$ & $<5$ \\
\hline 29 & $\mathrm{~F}$ & Idiopathic & Stillborn & 30 & $9 \cdot 3$ & Not recorded & $<5$ \\
\hline 30 & $\mathrm{~F}$ & Idiopathic & $<1$ & 30 & $9 \cdot 3$ & $6 \cdot 5$ & $<5$ \\
\hline 31 & $\mathrm{~F}$ & Idiopathic & $<1$ & 32 & $11 \cdot 0$ & $10 \cdot 0$ & $<5$ \\
\hline 32 & $\mathrm{~F}$ & Idiopathic, pulmonary hypoplasia & $<1$ & 32 & $11 \cdot 0$ & $8 \cdot 5$ & $<5$ \\
\hline 33 & $\mathbf{F}$ & Idiopathic, short limbed dwarf & $<1$ & 33 & $12 \cdot 0$ & $10 \cdot 2$ & $<5$ \\
\hline 34 & $\mathbf{F}$ & Idiopathic, pulmonary hypoplasia & $<1$ & 38 & $20 \cdot 4$ & 13.0 & $<5$ \\
\hline
\end{tabular}

*Denotes heart weight in excess of 2 standard deviations above the mean for gestation

ble. The three hydropic infants with endocardial fibroelastosis who had congenital heart malformations all had complex anomalies which in each case included some form of anatomical obstruction to right sided cardiac flow. Case 1 had tricuspid atresia and pulmonary valve hypoplasia; case 2 had pulmonary atresia; and case 5 had a hypoplastic right heart with tricuspid stenosis. The other infant with hydrops and a malformed heart, but in which endocardial fibroelastosis was not present, had a ventricular septal defect and a patent ductus arteriosus but no obstructive lesion.

\section{Discussion}

The heart may be regarded as a modified muscular artery. Structurally the endocardium corresponds to the arterial intima, the myocardium to the media, and the epicardium to the arterial adventitia. Analogies may also be made between their response to chronic stress. Sustained hypertension characteristically induces a diffuse intimal fibroelastic thickening in muscular arteries. ${ }^{5}$ At the cellular level it has been suggested that damage to cells in the arterial wall leads to the release of vasoactive substances which may serve as growth factors or act as intermediaries in their production. ${ }^{8}$ It seems reasonable to suppose that chronic myocardial stress may result in fibroelastic thickening of the endocardium by a similar mechanism.

In accordance with this there is a considerable body of evidence to suggest that many examples of endocardial fibroelastosis, including so-called primary cases, are associated with myocardial disease or stress. The cardiomyopathy of glycogen storage disease type II (Pompe's disease) is known to occur with endocardial fibroelastosis. ${ }^{4}$ In some examples of apparent primary endocardial fibroelastosis there is evidence of a cardiomyopathy in which the changes are subtle and seen only on ultrastructural examination. ${ }^{9}$ Congenital parvovirus infection occurred in one of our infants with endocardial fibroelastosis (case 7), the diagnosis being based on the presence of intranuclear inclusions in hepatic haemopoietic cells. ${ }^{10}$ Although no myocarditis was apparent and hydrops was probably a consequence of anaemia, it is interesting that epidemic myocarditis due to parvovirus occurs with endocardial fibroelastosis in dogs. ${ }^{11}$ Mild endocardial thickening, qualitatively similar to endocardial fibroelastosis, is also seen in chronic adult cardiac failure, especially in association with ventricular hypertrophy and coronary arterial disease. ${ }^{12}$ The more extensive and severe features of the condition in infancy probably reflect the generally greater growth potential in the younger age group.

The most common cause of hydrops fetalis is the high output heart failure accompanying intrauterine anaemia. Rhesus haemolytic disease is the most common cause in many countries and for this reason cases are often divided into rhesus and non-rhesus hydrops though, worldwide, intrauterine haemoglobinopathies, expecially $\alpha$-thalassaemia are commoner causes than blood group incompatibility. The pathophysiological processes implicated in the characteristic increase in interstitial fluid (fig 4) are not entirely clear; it has been suggested that hydrops is more related to hypoproteinaemia ${ }^{13}$ or to low oncotic pressure ${ }^{14}$ than anaemia. Structural cardiac malformations, myocardial ischaemia, and myocarditis are all associated with hydrops. ${ }^{6}$ Congenital arrhythmias-for example, paroxysmal atrial tachycardia ${ }^{15}$ and conduction abnormalities-may also cause the condition. Of relevance to the current study is the observation by Esscher and Scott of "endocardial fibrosis" in seven of nine neonatal deaths from heart block secondary to maternal systemic lupus erythematosis. ${ }^{16}$ In some cases of hydrops it is difficult to dissociate the relative parts played by several factors in its aetiology as with our example of parvovirus infection in which liver disease and congestive heart failure may both be implicated. In most series of 
Figure 4 A stillborn infant with hydrops fetalis, showing peripheral oedema and ascites.

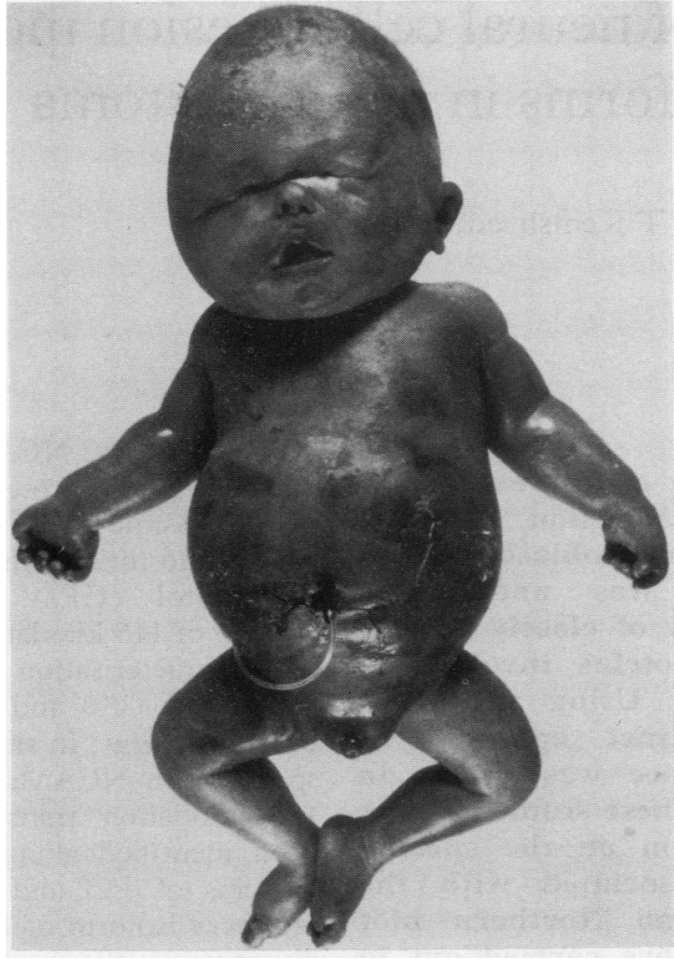

hydrops theres is always a proportion of cases where the cause remains unknown even after necropsy.

In the present series hydrops was unexplained in $11(32 \%)$, two of which showed endocardial fibroelastosis. Cardiac stress seemed to be important in the aetiology of the other eight cases of endocardial fibroelastosis, either from anaemia produced by rhesus haemolytic disease (cases 3, 6, and 9), parvovirus (case 7), cardiac malformation (cases 1, 2, and 5), or arteriovenous communication (case 4). In our study the congenital anomaly in each case involved a right sided valve stenosis, although left sided lesions have been more frequently associated with endocardial fibroelastosis in many series. ${ }^{3}$ Hydropic infants with obvious intrauterine cardiac stress who had developed endocardial fibroelastosis were more likely to have clinically important cardiomegaly than hydropic infants without endocardial fibroelastosis who had cardiac disease. This suggests that endocardial fibroelastosis is a reflection of the severity and chronicity of heart failure.
It could be argued that the cases presented in this study do not all display the pronounced endocardial fibroelastic thickening observed in the typical case of endocardial fibroelastosis (fig 1). It follows that endocardial changes will show a spectrum of severity ranging from the barely discernible microscopic thickening (cases 11 to 16), to examples with obvious microscopic change (figs 2 and 3), to the typical globular heart with pearly-white endocardium (fig 1), depending on the degree of haemodynamic stress and individual growth potential. We believe these entities differ quantitatively but that they are fundamentally similar.

The data presented here support the hypothesis that endocardial fibroelastosis is not a distinct disease but a non-specific response to myocardial damage similar to that seen in muscular arteries damaged by hypertension. A prospective study with detailed morphometry may be useful to elucidate further the relation between cardiac stress, hypertrophy, and endocardial fibroelastosis.

We are grateful to Dr Anna Kelsey for the use of the Seescan, to Dr John Rutherford for help with photography, and to Mrs A Yates for technical help.

1 Wigglesworth J. Perinatal pathology. Vol. 15. Major Problems in Pathology. Philadelphia: WB Saunders, 1984. 2 Black-Schaffer B. Infantile endocardial fibroelastosis. A suggested etiology. Arch Pathol 1957;63:281-306.

3 Still WJS. Endocardial fibroelastosis. Am Heart J 1961;61: 579-85.

4 Lurie PR. Endocardial fibroelastosis is not a disease. $A m J$ Cardiol 1988;62:468-9.

5 Olsen EGJ. Atlas of cardiovascular pathology. Current Histopathology Vol 12. Lancaster: MTP Press, 1987.

6 Keeling JW. Fetal hydrops. In: Keeling JW, ed. Fetal and neonatal pathology. Berlin: Springer Verlag, 1987;212-28.

7 Emery JL. The assessment of maturity and viability around the time of birth. In: Batson AJ, ed. Fetal and neonatal pathology. Eastbourne: Praeger Publishers, 1982:192-204.

8 Dzau VJ, Gibbons GH. Autocrine-paracrine mechanisms of vascular myocytes in systemic hypertension. Am J Cardiol 1987;60:991-1031.

9 Neustein HB, Lurie PR, Dahms B, Takahashi M. An Xlinked cardiomyopathy with abnormal mitochondria. Pediatrics 1979;64:24-9.

10 Anand A, Gray ES, Brown T, Clewley JP, Cohen BJ. Human parvovirus infection in pregnancy and hydrops Human parvovirus infection in pregnan

11 Levin S. Parvovirus. A possible etiologic agent in cardiomyopathy and endocardial fibroelastosis. Hum Pathol 1980;11:404-5.

12 Fisher ER, Davis ER. Observations concerning the pathogenesis of endocardial thickening in the adult heart. $\mathrm{Am}$ Heart $J$ 1958;58:553-61.

3 Phibbs RH, Johnson P, Tooley WH. Cardiorespiratory status of erythroblastic infants. Pediatrics 1974;53:13-23.

14 Baum JD, Harris D. Colloid osmotic pressure in erythroblasic fetalis. Br Med J 1972;i:601-3.

15 Radford DJ, Izukawa T, Rowe RD. Congenital paroxismal atrial tachycardia. Arch Dis Child 1976;51:613-7.

16 Esscher E, Scott JS. Congenital heart block and maternal systemic lupus erythematosis. Br Med J 1979;i:1235-8. 